\title{
Rancang Bangun Sistem Pakar Untuk Mendiagnosis Gangguan Kepribadian Histerik Menggunakan Metode Certainty Factor
}

\author{
Tri Nur Oktavia ${ }^{1}$, Diema Hernyka Satyareni ${ }^{2}$, Erliyah Nurul Jannah ${ }^{3}$ \\ ${ }^{1,2,3}$ Sistem Informasi, Fakultas Teknik, Universitas Pesantren Tinggi Darul 'Ulum (Unipdu), Jombang \\ E-mail: 1trieok38@gmail.com, ${ }^{2}$ diema_hs@yahoo.com, ${ }^{3}$ erliyah.nj@gmail.com
}

\begin{abstract}
Abstrak
Gangguan kepribadian histerik atau yang biasa dikenal dengan gangguan kepribadian histrionik merupakan gangguan kepribadian dengan karakter emosi yang meluap-luap, termasuk keinginan berlebihan untuk mendapatkan pujian. Penderita gangguan kepribadian histerik mempunyai tingkah laku yang dramatik dan bereaksi terhadap sesuatu secara berlebihan, serta selalu ingin diperhatikan. Banyak orang yang mengalami gangguan ini, terutama kalangan remaja. Namun sebagian besar dari penderita gangguan ini kurang menyadari kondisinya dan menolak untuk melakukan konsultasi ke psikolog atau psikiater. Oleh sebab itu, dibutuhkan suatu sistem pakar yang dapat membantu untuk mendiagnosis secara mandiri gangguan kepribadian histerik dan mampu memberikan solusi penanganan yang tepat. Sistem tersebut dibangun dengan menggunakan metode waterfall dan metode certainty factor sebagai metode kepakarannya. Hasil dari penelitian ini adalah sistem pakar berbasis web untuk mendiagnosis tingkat gangguan kepribadian histerik. Sistem akan menampilkan nilai kepastian dan tingkat gangguan kepribadian histerik yang dialami pengguna, serta solusi penanganannya. Uji hasil kepakaran dilakukan dengan cara membandingkan hasil diagnosis dari sistem dengan hasil diagnosis dari pakar. Hasil uji kepakaran menunjukkan bahwa hasil diagnosis sistem sudah mendekati kebenaran dari diagnosis seorang pakar. Nilai prosentase sistem sebesar $83,01 \%$ dan nilai prosentase pakar sebesar $83,3 \%$. Dengan adanya sistem pakar ini, masyarakat umum dapat melakukan diagnosis mandiri untuk mengetahui tingkat gangguan kepribadian histerik yang dialami serta penanganannya dengan mudah tanpa harus datang ke psikolog.
\end{abstract}

Kata kunci: gangguan kepribadian histrionik, emosi, sistem pakar, certainty factor.

\begin{abstract}
Histrionic personality disorder is a personality disorder which has caharcteristic like overflowing emotion and excessive desire for praise. They always want to be noticed. Many people are suffered from this disorder, especially teenagers. The majority of people who suffer from this disorder were less aware of their condition and refused to consult with a psychologist or psychiatrist. Therefore, it is necessary to build an expert system that can help people to diagnose histrionic personality disorder independently and able to give correct solution for it. The system is built using waterfall model and certainty factor as the expertise approach. The result of this study is a web based expert system for diagnosing the level of histrionic personality disorder. The system will display the certainty value, the level of histrionic personality disorder experienced by users, and handling solutions. Testing of the system is done by comparing the diagnosis result of the system with the expert result. The test showed that the result of diagnosis system is close to the diagnosis result of expert. The percentage of the system is $83.01 \%$ while the percentage of expert is $83.3 \%$. Given this expert system, the people will be able to perform selfdiagnostic to determine the level of histrionic personality disorder. They also obtain the solution of disorder without visiting a a psychologist or psychiatrist.
\end{abstract}

Key word: histrionic personality disorder, emotional, expert systems, certainty factor.

\section{Pendahuluan}

Masalah kesehatan jiwa di Indonesia merupakan masalah kesehatan masyarakat yang sangat penting dan harus mendapat perhatian sungguh-sungguh dari seluruh jajaran lintas sektor Pemerintah. Beban tingkat gangguan atau burden of disease tingkat gangguan jiwa di Tanah Air masih cukup besar. Berdasarkan data hasil Riset Kesehatan Dasar (Riskesdas) tahun 2013, menunjukkan bahwa prevalensi gangguan mental emosional yang ditunjukkan dengan gejala-gejala depresi dan kecemasan adalah sebesar 6\% untuk usia 15 tahun ke atas atau sekitar 14 juta orang (Depkes, 2014). 
Salah satu bentuk dari gangguan mental emosional adalah gangguan kepribadian histerik. Gangguan ini ditandai dengan perilaku yang bermacam-macam, dramatik, ekstrovet pada orang yang meluap-luap dan emosional (Kaplan, 1997). Penderita gangguan kepribadian histerik bisa memindahkan depresi dan rasa frustasi akibat keinginan yang tidak tercapai menjadi tingkat gangguan fisik. Penderita bisa benar-benar pingsan, padahal mereka tidak sakit sama sekali. Bahkan sebagian besar penderita gangguan ini, kurang menyadari kondisinya dan menolak untuk berkonsultasi dengan psikolog atau psikiater.

Penggunaan sistem pakar dapat menjadi solusi yang tepat dalam penanganan gangguan kepribadian histerik. Sistem pakar merupakan sistem berbasis komputer yang menggunakan pengetahuan, fakta dan teknik penalaran dalam memecahkan masalah yang biasanya hanya dapat dipecahkan oleh seorang pakar dalam bidang tertentu. Sistem pakar dirancang agar dapat melakukan penalaran seperti layaknya seorang pakar pada suatu bidang keahlian tertentu. Tujuan pengembangan sistem pakar sebenarnya bukan untuk menggantikan peran manusia, tetapi untuk mensubsitusikan pengetahuan manusia ke dalam bentuk sistem, sehingga dapat digunakan oleh orang banyak (Hartati \& Iswanti, 2008). Penerapan sistem pakar dalam bidang psikologi sebelumnya, telah banyak dikembangkan terutama masalah gangguan kepribadian (Johar \& Palupi, 2011) (Sitorus, 2013).

Penerapan sistem pakar diagnosis gangguan kepribadian pada penelitian sebelumnya (Johar \& Palupi, 2011), gambaran dari gangguan kepribadian yang ditampilkan tidak didukung perhitungan pada tiap gejala yang ada, sehingga penderita tidak mengetahui nilai kemungkinan gangguan kepribadian yang mereka alami. Selain itu penjelasan yang diberikan juga merupakan penjabaran masalah gangguan kepribadian secara umum. Dalam sistem pakar ini penjelasan menekankan pada gangguan kepribadian histerik yaitu untuk mengidentifikasi tingkat gangguan kepribadian histerik yang dialami pengguna sistem, memberikan nilai kepastian serta solusi penanganannya.

Metode certainty factor adalah metode yang digunakan untuk mengukur sesuatu apakah pasti atau tidak pasti dalam mendiagnosis dan mengidentifikasi suatu penyakit. Untuk pemberian nilai certainty factor ada 2. Yang pertama pemberian nilai certainty factor kaidah yang nilainya melekat pada suatu kaidah/rule tertentu dan besarnya nilai diberikan oleh pakar. Yang kedua pemberian nilai certainty factor yang diberikan oleh pengguna untuk mewakili derajat kepastian/keyakinan atas premis (misalnya gejala, kondisi, ciri) yang dialami pengguna. Pada implementasi sistem pakar akan terlihat bahwa nilai certainty factor yang diberikan oleh pengguna ada pada sesi konsultasi, sehingga sistem pakar selain meminta jawaban pengguna atas pertanyaan yang diajukan juga meminta masukan nilai certainty factor atas jawaban tersebut (Hartati \& Iswanti, 2008).

Oleh karena itu, penelitian ini mengembangkan sistem pakar untuk mendiagnosis gangguan kepribadian histerik menggunakan metode certainty factor. Dalam penerapan metode ini, seorang pakar akan menggambarkan tingkat keyakinan pakar dan tingkat keyakinan sistem yang didapat dari penderita terhadap gejala gangguan kepribadian histerik (Tabel 1), sehingga diperoleh nilai certainty factor untuk perhitungan tingkat gangguan kepribadian histerik yang dialami penderita tersebut. Hasil dari sistem pakar ini berupa tingkat gangguan kepribadian histerik (Tabel 2), nilai kepastian dan solusi penanganannya. Adapun tujuan dari penelitian ini adalah untuk: Merancang dan membangun aplikasi sistem pakar yang mampu mendiagnosis tingkat gangguan kepribadian histerik berdasarkan gejala yang ada, sehingga aplikasi ini dapat memberikan solusi penanganan yang tepat dan menerapkan metode certainty factor dalam sistem pakar yang digunakan sebagai gambaran seberapa besar gangguan kepribadian histerik yang dialami pengguna.

\section{Metode Penelitian}

\subsection{Sistem Pakar}

Sistem pakar merupakan sistem berbasis komputer yang menggunakan pengetahuan, fakta dan teknik penalaran dalam memecahkan masalah yang biasanya hanya dapat dipecahkan oleh seorang pakar dalam bidang tertentu. Sistem pakar dirancang agar dapat melakukan penalaran seperti layaknya seorang pakar pada suatu bidang keahlian tertentu. Dengan sistem pakar ini, orang awam pun dapat menyelesaikan masalah yang cukup rumit yang hanya dapat diselesaikan dengan bantuan para ahli. Tujuan pengembangan sistem pakar sebenarnya bukan untuk menggantikan peran manusia, tetapi untuk mensubsitusikan pengetahuan manusia kedalam bentuk sistem, sehingga dapat digunakan oleh orang banyak (Hartati \& Iswanti, 2008). 


\subsection{Gangguan Kepribadian}

Kaplan dan Saddock menjelaskan bahwa gangguan kepribadian adalah suatu varian dari sifat karakter tertentu di luar rentang yang ditemukan pada sebagian besar orang. Hanya jika sifat kepribadian tidak fleksibel, maladaptif, dan dapat menyebabkan gangguan fungsional yang bermakna atau penderitaan subyektif maka dimasukkan sebagai kelas gangguan kepribadian (Kaplan, 1997). Menurut DSM-IV (Diagnostic and Statistical Manual of Mental Disorders) Axis II membagi gangguan kepribadian menjadi tiga kelompok, yaitu:

1). Kelompok A, terdiri dari gangguan kepribadian paranoid, skizoid dan skizotipal. Orang dengan gangguan seperti ini seringkali tampak aneh dan eksentrik.

2). Kelompok B, terdiri dari gangguan kepribadian antisosial, ambang, histrionik/histerik dan narsistik. Orang dengan gangguan ini sering tampak dramatik, emosional, dan tidak menentu.

3). Kelompok $\mathrm{C}$, terdiri dari gangguan kepribadian menghindar, dependen dan obsesif-kompulsif, dan satu kategori yang dinamakan gangguan kepribadian yang tidak ditentukan (contohnya adalah gangguan kepribadian pasif-agresif dan gangguan kepribadian depresif). Orang dengan gangguan ini sering tampak cemas atau ketakutan.

Gangguan kepribadian histerik atau biasa disebut histrionic, menurut Kaplan dan Sadock merupakan gangguan kepribadian yang ditandai oleh perilaku bermacam-macam, dramatik, ekstrovet pada orang yang meluap-luap dan emosional. Penderita gangguan kepribadian menunjukkan perilaku mencari perhatian yang tinggi. Mereka cenderung memperbesar pikiran dan perasaan mereka, membuat segalanya terdengar lebih penting dibandingkan kenyataannya (Kaplan, 1997).

\subsection{Metode Cetainty Factor}

Menurut T. Sutojo, Teori Certainty Factor (CF) adalah teori yang digunakan untuk mengakomodasi ketidakpastian pemikiran (inexact reasoning) seorang pakar, yang diusulkan oleh Shortliffe dan Buchanan pada tahun 1975. Seorang pakar (misalnya dokter) sering menganalisis informasi yang ada dengan ungkapan dengan ketidakpastian, untuk mengakomodasi hal ini kita menggunakan $\mathrm{CF}$ guna menggambarkan tingkat keyakinan pakar terhadap masalah yang sedang dihadapi. Dalam mengekspresikan derajat kepastian, CF untuk mengasumsikan derajat kepastian seorang pakar terhadap suatu data (Sutojo, Mulyanto, \& Suhartono, 2011).

$C F[H, E] 1=C F[H] \times C F[E]$

Di mana, penjelasan dari persamaan (1) adalah sebagai berikut:

$C F[E] \quad$ : Certainty Factor evidence $\mathrm{E}$ yang dipengaruhi oleh evidence $\mathrm{E}$

$C F[H] \quad$ : Certainty Factor hipotesa dengan asumsi evidence diketahui dengan pasti, yaitu ketika $C F(E, e)=1$

$C F[H, E]:$ Certainty Factor hipotesa yang dipengaruhi oleh evidence e diketahui dengan pasti.

Certainty Factor untuk kaidah dengan kesimpulan yang serupa (similarly concluded rules):

$\mathrm{CF}_{\text {combine1,2 }}=\mathrm{CF}[\mathrm{H}, \mathrm{E}]_{1}+\mathrm{CF}[\mathrm{H}, \mathrm{E}]_{2}$

$\mathrm{CF}_{\text {combine }} \mathrm{CF}[\mathrm{H}, \mathrm{E}]_{\text {old }, 3}=\mathrm{CF}[\mathrm{H}, \mathrm{E}]_{\text {old }}+\mathrm{CF}[\mathrm{H}, \mathrm{E}]_{3} \times\left[1-\mathrm{CF}[\mathrm{H}, \mathrm{E}]_{\text {old }}\right]$

Di mana, penjelasan dari persamaan (2) adalah sebagai berikut:
$\mathrm{CF}_{\text {combine1,2 }}$
: Faktor kepastian kombinasi dari $\mathrm{CF}[\mathrm{H}, \mathrm{E}]_{1}$ dan $\mathrm{CF}[\mathrm{H}, \mathrm{E}]_{2}$
$\mathrm{CF}[\mathrm{H}, \mathrm{E}]_{1}$
: Ukuran kepercayaan hipotesis $H$, jika diberikan evidence $E_{l}$ pertama (antara 0 dan 1)
$\mathrm{CF}[\mathrm{H}, \mathrm{E}]_{2}$
: Ukuran kepercayaan hipotesis $H$, jika diberikan evidence $E_{2}$ pertama (antara 0 dan 1)
$\mathrm{CF}_{\text {combine }} \mathrm{CF}[\mathrm{H}, \mathrm{E}]_{\text {old }, 3} \quad$ : Faktor kepastian kombinasi paralel dari $\mathrm{CF}[\mathrm{H}, \mathrm{E}]_{2}$ dan $\mathrm{CF}[\mathrm{H}, \mathrm{E}]_{\text {old. }}$

\subsection{Analisis dan Perancangan Sistem}

Berikut ini adalah penerapan certainty factor pada sistem pakar untuk mendiagnosis gangguan kepribadian histerik yaitu: 
1. Pakar akan menentukan nilai $C F$ untuk masing-masing gejala sebagai berikut:

\begin{tabular}{|c|c|c|}
\hline$C F_{\text {pakar }}$ & Ingin selalu diperhatikan & $=0,4$ \\
\hline$C F_{\text {pakar }}$ & Egosentrik & $=0,4$ \\
\hline$C F_{\text {pakar }}$ & Emosi yang tidak stabil & $=0,4$ \\
\hline$C F_{\text {pakar }}$ & Perilaku sombong & $=0,2$ \\
\hline$C F_{\text {pakar }}$ & Lekas tersinggung & $=0,4$ \\
\hline$C F_{\text {pakar }}$ & Sering berdusta & $=0,4$ \\
\hline$C F_{\text {pakar }}$ & Berfantasi atau suka mengkhayal & $=0,6$ \\
\hline$C F_{\text {pakar }}$ & $\begin{array}{l}\text { Sering melakukan provokasi secara seksual yang tidak tepat } \\
\text { (menggoda) }\end{array}$ & $=0,2$ \\
\hline$C F_{\text {pakar }}$ & Kurang mampu menyatakan perasaan secara tepat & $=0,2$ \\
\hline$C F_{\text {pakar }}$ & Sering menggerakkan badan dalam berkomunikasi & $=0,6$ \\
\hline$C F_{\text {pakar }}$ & $\begin{array}{l}\text { Tidak merasa nyaman dalam situasi dimana ia tidak merupakan pusat } \\
\text { perhatian }\end{array}$ & 0,2 \\
\hline$C F_{\text {pakar }}$ & Mudah dipengaruhi oleh orang lain atau situasi & $=0,4$ \\
\hline$C F_{\text {pakar }}$ & $\begin{array}{l}\text { Menganggap hubungan menjadi lebih penting ketimbang keadaan } \\
\text { sebenarnya }\end{array}$ & $=0,4$ \\
\hline$C F_{\text {pakar }}$ & Reaksi berlebihan terhadap kejadian yang kecil & $=0,4$ \\
\hline$C F_{\text {pakar }}$ & Selalu memperhatikan penampilan & $=0,4$ \\
\hline$C F_{\text {pakar }}$ & $\begin{array}{l}\text { Tampak dangkal dan tidak sungguh-sungguh terhadap orang lain, } \\
\text { meski sepintas tampak hangat dan menarik }\end{array}$ & $=0,4$ \\
\hline$C F_{\text {pakar }}$ & $\begin{array}{l}\text { Bergantung pada orang lain; tidak berdaya dan selalu mencari jaminan } \\
\text { (dukungan) }\end{array}$ & \\
\hline
\end{tabular}

Tabel 1 adalah pengetahuan yang didapat dari pakar:

Tabel 1 Gejala Gangguan Kepribadian Histerik

\begin{tabular}{cl}
\hline Kode Gejala & \\
\hline G01 & Ingin selalu diperhatikan \\
G02 & Egosentrik \\
G03 & Emosi yang tidak stabil \\
G04 & Perilaku sombong \\
G05 & Lekas tersinggung \\
G06 & Sering berdusta \\
G07 & Berfantasi atau suka mengkhayal \\
G08 & Sering melakukan provokasi secara seksual yang tidak tepat (menggoda) \\
G09 & Kurang mampu menyatakan perasaan secara tepat \\
G010 & Sering menggerakkan badan dalam berkomunikasi \\
G011 & Tidak merasa nyaman dalam situasi di mana ia tidak merupakan pusat perhatian \\
G012 & Mudah dipengaruhi oleh orang lain atau situasi \\
G013 & Menganggap hubungan menjadi lebih penting ketimbang keadaan sebenarnya \\
G014 & Reaksi berlebihan terhadap kejadian yang kecil \\
G015 & Selalu memperhatikan penampilan \\
G016 & Tampak dangkal dan tidak sungguh-sungguh terhadap orang lain, meski sepintas \\
& tampak hangat dan menarik \\
G017 & Bergantung pada orang lain; tidak berdaya dan selalu mencari jaminan (dukungan) \\
\hline
\end{tabular}

Tabel 2 Tingkat Gangguan Kepribadian Histerik

\begin{tabular}{cc}
\hline Kode TGK & Tingkat Gangguan Kepribadian \\
\hline T1 & Sangat tinggi \\
T2 & Tinggi \\
T3 & Rata-rata \\
T4 & Rendah \\
\hline
\end{tabular}

18 | Register: Jurnal Ilmiah Teknologi Sistem Informasi, Januari 2015, Volume 1, Nomor 1 
Tabel 3 Aturan Nilai CF dan Tingkat Gangguan Kepribadian Histerik

\begin{tabular}{ccc}
\hline Kode Aturan & Aturan & Range \\
\hline AT1 & Sangat tinggi & $>0,83$ \\
AT2 & Tinggi & $0,82-0,61$ \\
AT3 & Rata-rata & $0,6-0,33$ \\
AT4 & Rendah & $<0,33$ \\
\hline
\end{tabular}

2. Selanjutnya penentuan nilai $C F$ dari pengguna yang berdasarkan pilihan jawaban pengguna yaitu sebagai berikut:

Ingin selalu diperhatikan $=$ Kadang

Egosentrik = Kadang

Emosi yang tidak stabil $=$ Tidak

$=0,4$

Perilaku sombong $=$ Tidak

$=0$,

$=0$

Lekas tersinggung $=$ Kadang

$=0$

Sering berdusta $=$ Tidak

$=0,4$

Berfantasi atau suka mengkhayal $=$ Sering

$=0$

Sering melakukan provokasi secara seksual yang

$=0,8$

tidak tepat (menggoda) $=$ Tidak

Kurang mampu menyatakan perasaan secara tepat $=$ Tidak Tahu

$=0$

Sering menggerakkan badan dalam berkomunikasi = Sangat Sering

$=0,2$

$=1$

Tidak merasa nyaman dalam situasi dimana ia tidak merupakan pusat perhatian $=$

Kadang

$=0,4$

$=0,2$

Menganggap hubungan menjadi lebih penting ketimbang keadaan sebenarnya $=$

Tidak

$=0$

Reaksi berlebihan terhadap kejadian yang kecil $=$ Sangat Sering $\quad=1$

Selalu memperhatikan penampilan $=$ Sering

$=0,8$

Tampak dangkal dan tidak sungguh-sungguh terhadap orang lain, meski sepintas tampak hangat dan menarik = Kadang

Bergantung pada orang lain; tidak berdaya dan selalu mencari jaminan (dukungan)

$=$ Tidak

\begin{tabular}{ccc}
\multicolumn{3}{c}{ Tabel 4 Nilai CF dari user } \\
\hline No & Jawaban & Nilai CF \\
\hline 1 & Tidak & 0 \\
2 & Tidak tau & 0,2 \\
3 & Kadang & 0,4 \\
4 & Cukup sering & 0,6 \\
5 & Sering & 0,8 \\
6 & Sangat sering & 1 \\
\hline
\end{tabular}

3. Menghitung nilai $C F$ (Tabel 4) dari tiap gejala yang dipilih pengguna dengan nilai $C F$ pakar yaitu:

$$
\begin{aligned}
& C F[H, E]_{1}=C F[H]_{1} \times C F[E]_{1}=0,4 \times 0,4=0,16 \\
& C F[H, E]_{2}=C F[H]_{2} \times C F[E]_{2}=0,4 \times 0,4=0,16 \\
& C F[H, E]_{3}=C F[H]_{3} \times C F[E]_{3}=0,4 \times 0=0 \\
& C F[H, E]_{4}=C F[H]_{4} \times C F[E]_{4}=0,2 \times 0=0 \\
& C F[H, E]_{5}=C F[H]_{5} \times C F[E]_{5}=0,4 \times 0,4=0,16 \\
& C F[H, E]_{6}=C F[H]_{6} \times C F[E]_{6}=0,4 \times 0=0 \\
& C F[H, E]_{7}=C F[H]_{7} \times C F[E]_{7}=0,6 \times 0,8=0,48 \\
& C F[H, E]_{8}=C F[H]_{8} \times C F[E]_{8}=0,2 \times 0=0 \\
& C F[H, E]_{9}=C F[H]_{9} \times C F[E]_{9}=0,2 \times 0,2=0,04
\end{aligned}
$$




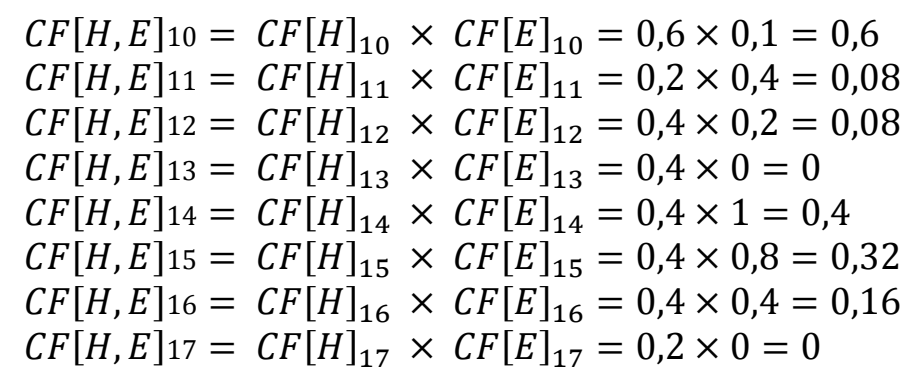

4. Langkah yang terakhir adalah mengkombinasikan nilai $C F$ dari masing-masing kaidah.

$$
\begin{aligned}
& C F_{(A)}=C F\left[H, E_{1}\right]^{\left[E^{2}\right]} \\
& =C F\left(E_{1}\right)+\left(C F\left(E_{2}\right) \times\left[1-C F\left(E_{1}\right)\right]\right)=0,16+(0,16 \times(1-0,16))=0,29 \\
& C F_{(B)}=C F\left[H, E_{3}\right]^{[C F(A)]} \\
& =C F\left(E_{3}\right)+\left(C F\left(E_{(A)}\right) \times\left[1-C F\left(E_{3}\right)\right]\right)=0+(0,29 \times(1-0))=0,29 \\
& C F_{(C)}=C F\left[H, E_{4}\right]^{\left[C F_{(B)}\right]} \\
& =C F\left(E_{4}\right)+\left(C F\left(E_{(B)}\right) \times\left[1-C F\left(E_{4}\right)\right]\right)=0+(0,29 \times(1-0))=0,29 \\
& C F_{(D)}=C F\left[H, E_{3}\right]^{\left[C F_{(C)}\right]} \\
& =C F\left(E_{5}\right)+\left(C F\left(E_{(C)}\right) \times\left[1-C F\left(E_{5}\right)\right]\right)=0,16+(0,29 \times(1-0,16))=0,404 \\
& C F_{(E)}=C F\left[H, E_{6}\right]^{\left[C F_{(D)}\right]} \\
& =C F\left(E_{6}\right)+\left(C F\left(E_{(D)}\right) \times\left[1-C F\left(E_{6}\right)\right]\right)=0+(0,404 \times(1-0))=0,404 \\
& C F_{(F)}=C F\left[H, E_{7}\right]^{\left[C F_{(E)}\right]} \\
& =C F\left(E_{7}\right)+\left(C F\left(E_{(E)}\right) \times\left[1-C F\left(E_{7}\right)\right]\right)=0,48+(0,404 \times(1-0,48))=0,69 \\
& C F_{(G)}=C F\left[H, E_{8}\right]^{\left[C F_{(F)}\right]} \\
& =C F\left(E_{8}\right)+\left(C F\left(E_{(F)}\right) \times\left[1-C F\left(E_{8}\right)\right]\right)=0+(0,69 \times(1-0))=0,69 \\
& C F_{(H)}=C F\left[H, E_{9}\right]^{\left[C F_{(G)}\right]} \\
& =C F\left(E_{9}\right)+\left(C F\left(E_{(G)}\right) \times\left[1-C F\left(E_{9}\right)\right]\right)=0,04+(0,69 \times(1-0,04))=0,7 \\
& C F_{(I)}=C F\left[H, E_{10}\right]^{\left[C F_{(H)}\right]} \\
& =C F\left(E_{10}\right)+\left(C F\left(E_{(H)}\right) \times\left[1-C F\left(E_{10}\right)\right]\right)=0,6+(0,7 \times(1-0,6))=0,88 \\
& C F_{(J)}=C F\left[H, E_{11}\right]^{\left[C F_{(I)}\right]} \\
& =C F\left(E_{11}\right)+\left(C F\left(E_{(I)}\right) \times\left[1-C F\left(E_{11}\right)\right]\right)=0,08+(0,88 \times(1-0,08))=0,89 \\
& \left.C F_{(K)}=C F\left[H, E_{12}\right]^{[C F(J)}\right] \\
& =C F(12)+\left(C F\left(E_{(J)}\right) \times\left[1-C F\left(E_{12}\right)\right]\right)=0,08+(0,89 \times(1-0,08))=0,9 \\
& C F_{(L)}=C F\left[H, E_{13}\right]^{\left[C F_{(K)}\right]} \\
& =C F\left(E_{13}\right)+\left(C F\left(E_{(K)}\right) \times\left[1-C F\left(E_{13}\right)\right]\right)=0+(0,9 \times(1-0))=0,9 \\
& C F_{(M)}=C F\left[H, E_{14}\right]^{\left[C F_{(L)}\right]} \\
& =C F\left(E_{14}\right)+\left(C F\left(E_{(L)}\right) \times\left[1-C F\left(E_{14}\right)\right]\right)=0,4+(0,9 \times(1-0,4))=0,94 \\
& \left.C F_{(N)}=C F\left[H, E_{15}\right]^{[C F(N)}\right] \\
& =C F\left(E_{15}\right)+\left(C F\left(E_{(M)}\right) \times\left[1-C F\left(E_{15}\right)\right]\right)=0,32+(0,94 \times(1-0,32))=0,959 \\
& C F_{(O)}=C F\left[H, E_{16}\right]^{\left[C F_{(N)}\right]} \\
& =C F\left(E_{16}\right)+\left(C F\left(E_{(N)}\right) \times\left[1-C F\left(E_{16}\right)\right]\right)=0,16+(0,959 \times(1-0,16))=0,966 \\
& C F_{(P)}=C F\left[H, E_{17}\right]^{[C F(O)]} \\
& =C F\left(E_{17}\right)+\left(C F\left(E_{(O)}\right) \times\left[1-C F\left(E 1_{7}\right)\right]\right)=0+(0,966 \times(1-0))=0,966
\end{aligned}
$$

Dari perhitungan secara manual di atas, diperoleh nilai CF dari masukan gejala yang merujuk ke gangguan kepribadian histerik adalah 0,966. Menurut Tabel 3 hal ini menunjukkan bahwa penderita mengalami tingkat gangguan kepribadian histerik sangat tinggi. 


\section{Hasil Penelitian dan Pembahasan}

Pengujian sistem dilakukan dengan uji kepakaran yaitu dengan membandingkan hasil diagnosis dari sistem dengan hasil diagnosis pakar. Contoh kasus dapat dilihat di bawah ini:

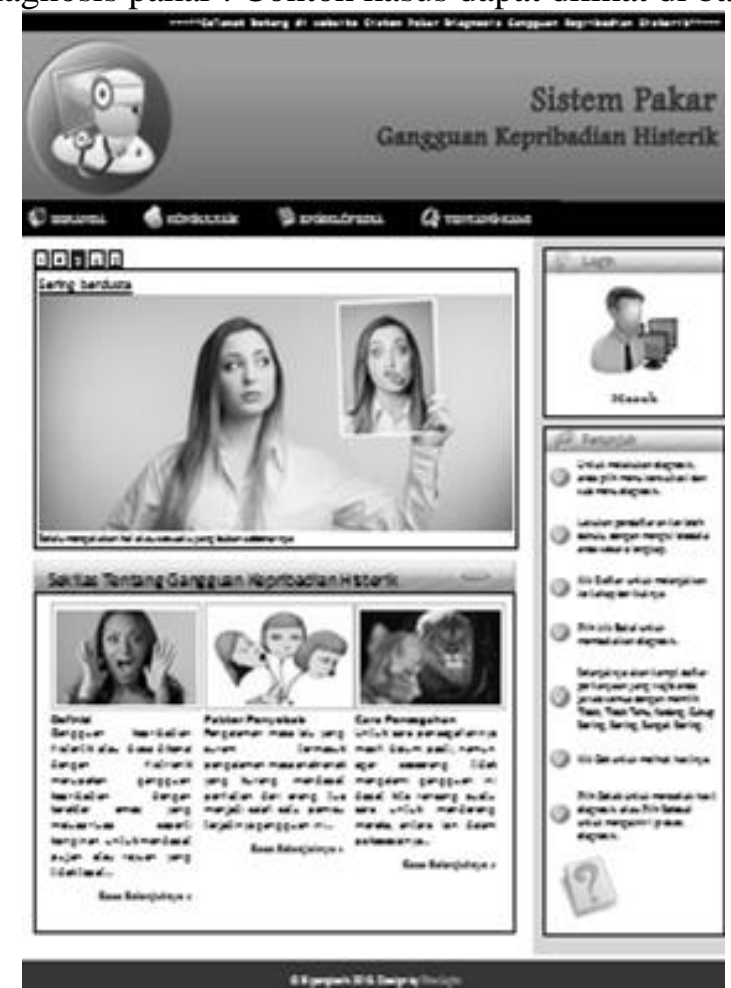

Gambar 1 Halaman Utama

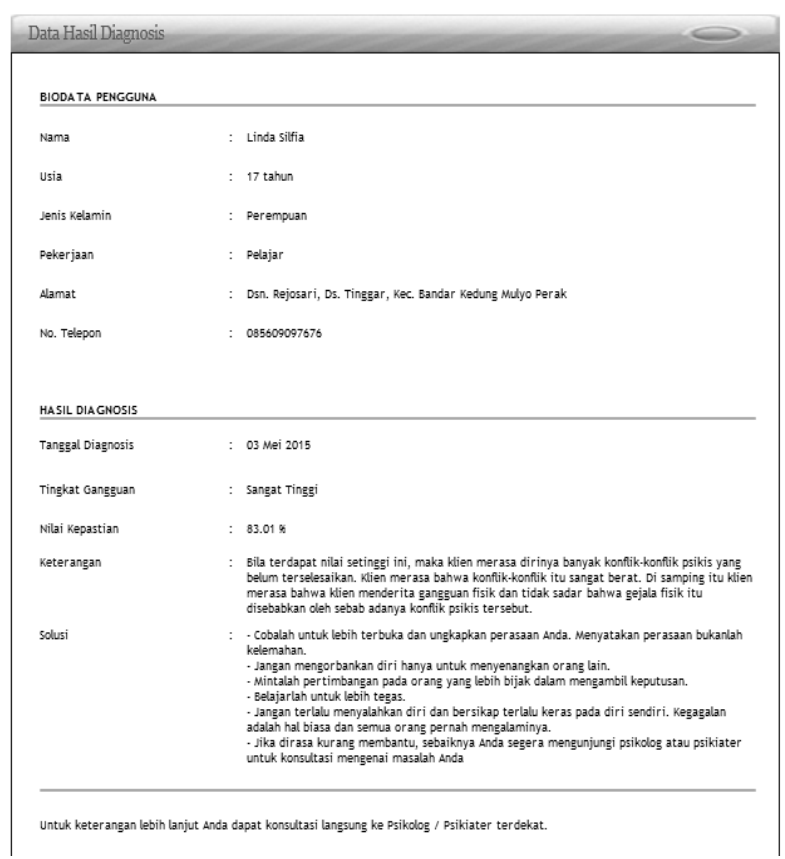

Gambar 2 Halaman Hasil Diagnosis

Seorang remaja putri berusia 17 tahun, dia selalu memperhatikan penampilannya. Dia termasuk anak yang manja. Dia berkata bahwa seluruh keinginannya harus dipenuhi jika tidak ia akan marahmarah. Terkadang dia berani berbohong untuk mendapatkan keinginannya. Dia juga sering membayangkan hal yang belum terjadi. Dia mempunyai perilaku yang angkuh, dia dapat menunjukan keriangan yang berlebihan saat bertemu dengan seseorang atau menjadi sangat marah saat seseorang tidak menyadari penampilan barunya. 
Dari kasus di atas, psikolog melakukan pemeriksaan dan analisis masalah atau kasus yang dialami klien. Hasil diagnosis pakar menyatakan klien termasuk mengalami gangguan kepribadian histerik dengan tingkat gangguan yang sangat tinggi, di mana nilai kepastiannya adalah 83,3\%. Gambar 1 adalah gambar dari implementasi sistem pakar gangguan kepribadian histerik.

Adapun saat klien, menggunakan sistem pakar diagnosis gangguan kepribadian histerik adalah sebagai berikut:

\begin{tabular}{|c|c|}
\hline Ingin selalu diperhatikan $=$ Cukup Sering & $=0,6$ \\
\hline Egosentrik $=$ Kadang & $=0,4$ \\
\hline Emosi yang tidak stabil $=$ Kadang & $=0,4$ \\
\hline Perilaku sombong $=$ Cukup Sering & $=0,6$ \\
\hline Lekas tersinggung $=$ Tidak & $=0$ \\
\hline Sering berdusta $=$ Kadang & $=0,4$ \\
\hline Berfantasi atau suka mengkhayal $=$ Kadang & $=0,4$ \\
\hline Sering melakukan provokasi secara seksual yang tidak tepat (menggoda) $=$ Tidak & $=0$ \\
\hline Kurang mampu menyatakan perasaan secara tepat $=$ Kadang & $=0,4$ \\
\hline Sering menggerakkan badan dalam berkomunikasi $=$ Tidak & $=0$ \\
\hline $\begin{array}{l}\text { Tidak merasa nyaman dalam situasi dimana ia tidak merupakan pusat perhatian } \\
=\text { Tidak }\end{array}$ & $=0$ \\
\hline Mudah dipengaruhi oleh orang lain atau situasi $=$ Tidak & $=0$ \\
\hline $\begin{array}{l}\text { Menganggap hubungan menjadi lebih penting ketimbang keadaan sebenarnya } \\
=\text { Tidak }\end{array}$ & $=0$ \\
\hline Reaksi berlebihan terhadap kejadian yang kecil $=$ Kadang & $=0,4$ \\
\hline Selalu memperhatikan penampilan = Cukup Sering & $=0,6$ \\
\hline $\begin{array}{l}\text { Tampak dangkal dan tidak sungguh-sungguh terhadap orang lain, meski sepintas } \\
\text { tampak hangat dan menarik = Tidak }\end{array}$ & $=0$ \\
\hline $\begin{array}{l}\text { Bergantung pada orang lain; tidak berdaya dan selalu mencari jaminan } \\
\text { (dukungan) = Tidak Tahu }\end{array}$ & 0,2 \\
\hline
\end{tabular}

Dari pilihan gejala-gejala di atas, hasil diagnosis sistem menunjukkan bahwa klien mengalami gangguan kepribadian histerik dengan tingkat gangguan yang sangat tinggi dengan nilai kepastian $83,01 \%$. Jadi, dapat disimpulkan bahwa akurasi sistem pakar berdasarkan hasil diagnosis pakar dengan hasil diagnosis sistem yang menunjukkan bahwa sistem pakar ini dapat berfungsi dengan cukup baik sesuai dengan diagnosis pakar.

Berdasarkan analisis dan perancangan sistem hingga implementasi dan pengujian sistem, maka dapat disimpulkan bahwa:

1. Berdasarkan hasil uji kepakaran yang dilakukan sistem dan pakar menunjukkan bahwa hasil sistem dalam mendiagnosis gangguan kepribadian histerik sudah mendekati kebenaran seorang pakar dengan dibuktikan hasil presentase diagnosis dengan pakar (psikolog) sebesar 83,3\% dan hasil prosentase diagnosis sistem $83,01 \%$.

2. Penerapan metode certainty factor dapat memperkuat diagnosis yang dihasilkan karena sistem mempunyai nilai sehingga tingkat kepastian lebih akurat.

3. Tingkat gangguan kepribadian histerik akan semakin tinggi, jika saat melakukan diagnosis pemilihan gejala semakin banyak (Muslim, 2011). Karena informasi yang diinputkan banyak, sistem akan menghitung nilai kepastian yang semakin besar sehingga tingkat gangguan kepribadian histerik yang dialami pengguna juga semakin tinggi.

Dari kesimpulan yang ada dapat diketahui bahwa penelitian yang dilakukan masih terdapat kekurangan. Oleh karena itu, diperlukan saran-saran untuk kebaikan pengembangan sistem lebih lanjut, diantaranya:

1. Perlu dilakukan perbaikan dalam penambahan sesi tanya jawab mengenai masalah gangguan kepribadian histerik yang dialami ataupun masalah gangguan jiwa lainnya.

2. Perbaikan user interface agar lebih menarik.

Perlu diadakan penambahan pengetahuan untuk gangguan kepribadian lainnya beserta gejalagejalanya, sehingga informasi yang dimiliki akan semakin luas dan banyak. 


\section{Kesimpulan}

Berdasarkan analisis dan perancangan sistem hingga implementasi dan pengujian sistem, maka dapat disimpulkan bahwa: Berdasarkan hasil uji kepakaran yang dilakukan sistem dan pakar menunjukkan bahwa hasil sistem dalam mendiagnosis gangguan kepribadian histerik sudah mendekati kebenaran seorang pakar dengan dibuktikan hasil presentase diagnosis dengan pakar (psikolog) sebesar $83,3 \%$ dan hasil prosentase diagnosis sistem $83,01 \%$.

Penerapan metode certainty factor dapat memperkuat diagnosis yang dihasilkan karena sistem mempunyai nilai sehingga tingkat kepastian lebih akurat. Tingkat gangguan kepribadian histerik akan semakin tinggi, jika saat melakukan diagnosis pemilihan gejala semakin banyak (Muslim, 2011). Karena informasi yang diinputkan banyak, sistem akan menghitung nilai kepastian yang semakin besar sehingga tingkat gangguan kepribadian histerik yang dialami pengguna juga semakin tinggi. Dari kesimpulan yang ada dapat diketahui bahwa penelitian yang dilakukan masih terdapat kekurangan. Oleh karena itu, diperlukan saran-saran untuk kebaikan pengembangan sistem lebih lanjut, diantaranya. Perlu dilakukan perbaikan dalam penambahan sesi tanya jawab mengenai masalah gangguan kepribadian histerik yang dialami ataupun masalah gangguan jiwa lainnya. Perbaikan user interface agar lebih menarik. Perlu diadakan penambahan pengetahuan untuk gangguan kepribadian lainnya beserta gejala-gejalanya, sehingga informasi yang dimiliki akan semakin luas dan banyak.

\section{Referensi}

Depkes. (2014, Oktober 10 ). Stop Stigma dan Diskriminasi terhadap Orang Dengan Gangguan Jiwa $(O D G J)$.

Hartati, S., \& Iswanti, S. (2008). Sistem Pakar dan Pengembangannya. Yogyakarta: Graha Ilmu.

Johar, A., \& Palupi, D. D. (2011). Implementasi Metode Frame Untuk Mendiagnosa Gangguan Kepribadian Dramatik Menggunakan Sistem Pakar. Seminar Nasional Aplikasi Teknologi Informasi 2011 (SNATI 2011). Yogyakarta.

Kaplan, H. I. (1997). Sinopsis Psikiatri: Ilmu Pengetahuan Perilaku Psikiatri Klinis. Jakarta: Binarupa Aksara.

Muslim, R. (2011). Buku Saku Diagnosis Gangguan Jiwa Rujukan Ringkas dari PPDGJ III. Jakarta: Bagian Ilmu Kedokteran Jiwa FK Unika Atma Jaya.

Sitorus, R. (2013). Pembangunan Aplikasi Sistem Pakar Analisis Tingkat gangguan Gangguan Kepribadian Menggunakan Teorema Bayes. Yogyakarta: Universitas Atma Jaya Yogyakarta.

Sutojo, T., Mulyanto, E., \& Suhartono, V. (2011). Kecerdasan Buatan . Yogyakarta: Andi. 